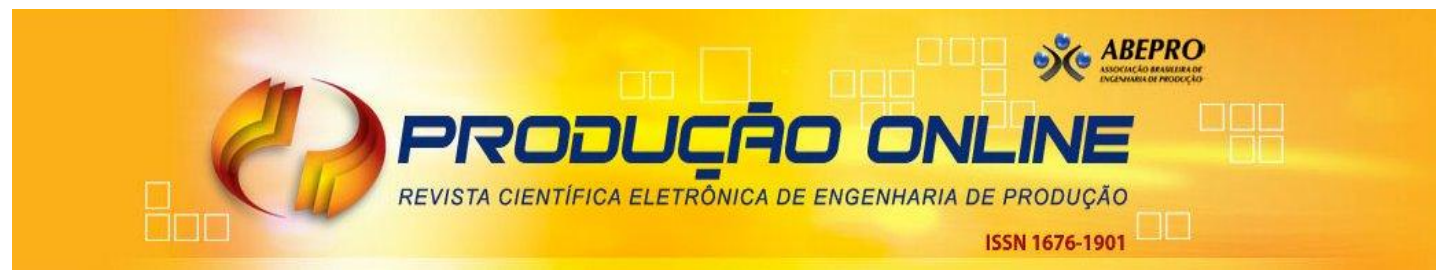

\title{
AVALIAÇÃO DO NÍVEL DE SERVIÇO LOGÍSTICO DE UMA EMPRESA DISTRIBUIDORA DE AUTOPEÇAS
}

\section{EVALUATION OF LOGISTIC SERVICE LEVEL OF AN AUTOMOTIVE PARTS DISTRIBUTION FIRM}

\author{
Fábio Germano Cardoso*E-mail: fabiocardoso98@gmail.com \\ José Geraldo Vidal Vieira* E-mail: igvvidal@ufscar.br \\ João Eduardo Azevedo Ramos Silva *E-mail: jesilva@ufscar.br \\ Adelson Martins Figueiredo *E-mail: adelson@ufscar.br \\ *Universidade Federal de São Carlos (UFSCar), Sorocaba, SP
}

\begin{abstract}
Resumo: As teorias acerca da gestão de estoques têm um viés eminentemente matemático e estatístico, mas pouca atenção é dada à discussão das necessidades inerentes do ambiente competitivo no qual as empresas estão inseridas, como nível de serviço ótimo e respectivos custos de inventário. O objetivo desta pesquisa é avaliar o nível de serviço logístico de uma empresa distribuidora de autopeças. Por meio de um estudo de caso, foi realizada uma análise de regressão nos dados históricos de inventário e vendas mensais entre 2008 e 2012, o que permitiu encontrar a curva real de lucro em função do nível de serviço. O nível serviço ótimo, encontrado por meio da derivação dessa curva, foi comparado com os níveis de serviço praticados pela empresa. Os resultados dessa análise apontam para o fato de que essa teoria não é suficiente para, sozinha, explicar como a empresa estudada define seu nível de serviço.
\end{abstract}

Palavras-chave: Nível de serviço. Cadeias de suprimentos. Logística de distribuição. Política de estoques. Gestão da demanda.

Abstract: The stock management theories have a mathematical and statistical trend, usually failing in exposing the business side of decisions regarding inventory costs and the related service levels. The article tests the theory of defining the service level by building the profit mathematical model, using for such some available historical data. With this theory it is possible to find the optimal service level by deriving the profit curve and equaling the marginal profit to zero. The research is characterized as a case research of an auto parts distribution company. The calculated optimal service level was compared to the data available from the company. The results of such analysis revealed the fact that only the theory of calculating the optimal service level through the profit curve derivation is not sufficient to explain how the company defines which service level is going to be used.

Keywords: Service level. Supply chain. Distribution logistics. Stock policies. Demand management.

\section{INTRODUÇÃO}

Uma economia global pode ser definida como sendo uma economia na qual os bens, serviços, pessoas, habilidades e ideias movem-se livremente através das fronteiras geográficas (HITT; IRELAND; HOKISSON, 2003). Por isso, vários fatores alteram a demanda: preços dos produtos, que devem ser enxergados atualmente 
dentro de um ambiente de competição global; a renda das pessoas ou a sua capacidade de gastar e investir; preços de produtos relacionados e que podem substituir o seu produto em um ambiente competitivo; os gostos de cada indivíduo e suas expectativas (MANKIW, 2001).

A cadeia automotiva é um expoente dessa competição global, pois tem passado por mudanças na tentativa de deixarem suas operações mais eficazes, buscando atender melhor ao desejo de seus clientes (FERREIRA; ALCÂNTRA, 2011). O fato de a empresa possuir os recursos tecnológicos adequados, capacidade instalada satisfatória, uma rede de distribuição eficaz e capaz de atingir aos clientes, desenvolvimento de fontes de suprimentos adequadas e confiáveis, além de uma localização geográfica economicamente viável, consiste em fator chave de sucesso dentro das estratégias para satisfação da demanda (WRIGHT; KROLL; PARNELL, 2000). Vale ressaltar que a gestão da demanda e da capacidade de produção na distribuição de autopeças é custosa, tendo em vista o longo tempo para construção de fábricas e centros de distribuição, contratação de recursos e as altas quantias de dinheiro envolvidas (GAITHER; FRAZIER, 2002).

A relevância do sistema logístico é o de fornecer um nível de serviço desejado ao consumidor pelo menor custo (KOTLER; ARMSTRONG, 1995). Portanto, tornase importante o estudo dos serviços logísticos, pois o caminho para a competitividade sustentável pode estar no seu aprimoramento (MENTZER; WILLIAMS, 2001). Nível de serviço logístico, como medida do sistema logístico, tem a função de medir a satisfação dos clientes de acordo com várias dimensões (MENTZER; GOMES; KRAPFEL, 1989).

A exposição de uma visão estratégica da logística é tema de uma pequena fração das publicações de artigos (WANKE; 2005). Vê-se que a gestão estratégica do nível de serviço é chave para o estabelecimento do fluxo de bens e serviços e uma condição importante para o sucesso e o estabelecimento de uma vantagem competitiva sustentável. Quando as empresas tomam boas decisões em relação ao tipo de distribuição e ao tipo de produção, elas obtêm melhores resultados nos níveis de serviço do varejo e, portanto, para o cliente final, que outras que não o fazem (WANKE et al; 2006). Sendo a definição do nível de serviço um tema central nas decisões logísticas, a principal contribuição dessa pesquisa é lançar luz sobre a 
aplicabilidade e discussão a partir de modelos teóricos para a definição de indicadores de serviço logístico.

O objetivo da pesquisa é avaliar o nível de serviço ótimo por meio da aplicação da teoria em uma empresa atacadista de autopeças e compará-lo com os números praticados pela empresa. O primeiro passo para essa avaliação foi testar a aplicação da teoria para cálculo do nível de serviço ótimo descrita em Ballou (2006).

A pesquisa inicia com uma revisão na literatura com o objetivo de investigar os principais fatores que impactam o nível de serviço nas dimensões estratégica, tática e operacional. A revisão com base nessas dimensões ajuda ao leitor entender melhor o conceito de nível de serviço que se apresenta muito mais do que um conceito no campo operacional, e certamente servirá de base para discussão dos resultados encontrados por esta pesquisa. Após uma breve explicação da metodologia utilizada, o trabalho expõe os resultados de um estudo de caso, feito com base na investigação de informações de arquivos de dados. A análise executada visou a testar a teoria sobre a definição do nível de serviço como função do lucro marginal nulo e na etapa da conclusão pode-se acompanhar os resultados da pesquisa.

\section{REVISÃO DA LITERATURA}

A redução de custos logísticos tem se tornado um critério qualificador e o nível de serviço é um critério cada vez mais importante e diferenciador entre as atividades logísticas de uma empresa, ou seja, um critério ganhador de pedido (SLACK, 2002).

O termo nível de serviço logístico tem significado amplo e é retratado na literatura por meio de diversas dimensões ou elementos (MARCHESINI, ALCANTRA; 2012). De uma maneira geral encontram-se componentes estratégicos do nível de serviço, focados no gerenciamento do relacionamento com o cliente além do gerenciamento de suas expectativas; componentes táticos, focados no relacionamento entre manufatura e distribuição e gestão de estoques e de localização; e componentes operacionais, ligados principalmente na gestão das variáveis do estoque como quantidades a pedir, lead times, etc. 
A presente revisão inicia-se pelos aspectos estratégicos do nível de serviço, explorando a literatura e buscando pelos diversos significados que essa dimensão logística pode ter. $\mathrm{Na}$ busca pelos aspectos táticos do nível de serviço, a pesquisa inicia a apresentação de como as variáveis de pesquisa se relacionam na literatura. Essas variáveis são: nível de serviço, custo logístico e receita advinda do serviço logístico. Por fim, os aspectos operacionais dão o apoio necessário à execução da pesquisa, explorando a metodologia para o cálculo do nível de serviço ótimo. Nos aspectos operacionais, busca-se também apresentar contrapontos presentes na literatura que mostrem que a escolha do nível de serviço a ser executado pelas empresas é uma ação que pondera outros aspectos estratégicos além da busca pelo ponto de receita marginal igual a zero.

\subsection{Fatores estratégicos e o nível de serviço}

Devido aos ganhos de produtividade advindos da especialização na produção, as pessoas optam por produzirem um conjunto pequeno de produtos $\mathrm{e}$ assim realizarem o comércio para aumentarem o seu bem-estar (MANKIW, 2001). A logística aparece como sendo um conceito intrinsecamente ligado à macroeconomia, e essencial para satisfazer a necessidade de localização, pois se faz necessário aproximar o que é produzido do consumidor final no momento do consumo, por meio de um nível de serviço adequado. Apenas a produção, sem a cooperação com a logística, não é suficiente para atender ao cliente satisfatoriamente, em função das tendências atuais de mercado e de não permitir a conversão de um desejo em uma venda (KONIJNENDIJK, 1991). Portanto, o nível de serviço prestado ao cliente ganha importância à medida que a manutenção e a melhora dos serviços logísticos têm destaque entre empresas concorrentes.

Como o comércio é uma necessidade macroeconômica, empresas, pessoas e governos, trabalham para maximizar seus resultados advindos da troca e assim apelam ao marketing. No entanto, a equiparação da tecnologia e da qualidade na produção de diversos produtos assim como a massificação da informação e dos canais de promoção utilizados pelas empresas tornou a diferenciação por produto, preço e promoção uma atividade árdua. O nível de serviço transformou-se, então, em um diferencial competitivo importante e, portanto estratégico, em razão da 
necessidade de um misto de ativos, muitas vezes caros, de uma tecnologia de processos e da cultura de cada organização. Isso tudo torna a logística de cada empresa única e de difícil equiparação pelos concorrentes (MENTZER; WILLIAMS, 2001).

O nível de serviço logístico, de várias maneiras, confunde-se com a gestão de serviços em si. Quando pesquisa-se acerca das dimensões de desempenho das organizações de serviços, encontram-se vários fatores que são comuns aos serviços logísticos propriamente ditos, entre eles: confiabilidade, flexibilidade, preço, qualidade, comunicação, etc. (JUNIOR, MIYAKE; 2011). Isso traz uma dimensão importante ao serviço logístico que é a gestão do cliente.

Considerando o raciocínio acima, o nível de serviço logístico pode ser conceituado como sendo o grau de confiabilidade com a qual uma cadeia de suprimentos consegue gerar valor para o cliente e vantagem competitiva para a empresa. Isso pode ser feito por meio do aumento de sua reputação e da gestão de serviços, transporte, estoques e informação, por meio da propagação dos dois últimos ao longo dos elos da cadeia. Ele depende primariamente da percepção dos compradores sobre suas necessidades e não somente dos fatores endógenos da empresa ou função de variáveis estatísticas puras. Umas das principais funções do nível de serviço é o relacionamento com o cliente, o que corrobora o conceito de que os serviços logísticos e de marketing devem estar ligados para que a organização seja bem sucedida no serviço ao cliente (EMERSON, GRIM; 1996).

\subsection{Fatores táticos e o nível de serviço}

O gerenciamento da demanda possui, em alguma medida, algum nível de incerteza, dado o grande número de variáveis que o influenciam. $O$ equilíbrio entre capacidade e demanda é chave para a empresa, pois pode gerar tanto altos lucros no caso de estarem alinhadas, quanto grandes perdas caso estejam descompassadas (SLACK; CHAMBERS; JOHNSTON, 2007). Esse equilíbrio leva a um aumento do nível de serviço.

Outra forma de elevar o nível de serviço é aumentar as receitas proporcionalmente à diminuição dos custos logísticos. Em se tratando de elevar a receita, faz-se necessário o estudo de uma boa previsão de demanda, na medida 
em que o entendimento do seu tipo, os efeitos da propagação acumulada dessa demanda ao longo da cadeia, os efeitos gerados pela correta estratificação dos itens e o melhor método para prevê-la geram níveis de serviço maiores (GAVIOLLI; BARBIERI, 2007). O efeito das incertezas da demanda e dos resultados de sua propagação, conhecido como efeito chicote, pode elevar os custos logísticos além de reduzir o nível de serviço (FREITAS et al, 2010). Os fatores acima adquirem nova dimensão quando se tratam de produtos novos e merecem análises específicas (OLIVEIRA E SILVA; BERTRAND, 2008).

A demanda independente impõe uma decisão de como se deve realizar a sua previsão. Existem várias maneiras de separar a demanda independente em tipos, o que, como consequência, desencadeia uma série de outras decisões de como prevê-la, cada uma gerando um nível de serviço como consequência (DE LEEUW; VAN GOOR; VAN AMSTEL, 1999).

Não basta prever o quanto será vendido, mas também onde. A dimensão espacial da demanda indica onde a demanda irá se manifestar o que servirá como fundamento para localização de armazéns ou estoques. A questão de posicionamento dos estoques é central, uma vez que, por um lado tem crescido a importância de se reduzir custos de capital, obsolescência e espaço, e por outro, existe a necessidade de se melhorar o nível de serviço em função da crescente competição global (WHYBARK; YANG, 1996).

Por último, existem estratégias de produção que alteram o resultado do nível de serviço para um dado nível de estoque. Elas também têm a capacidade de oferecer diferentes níveis de serviço para expectativas distintas dos clientes como rapidez, personalização, pronta-entrega, etc.. A combinação de dois fatores, postergação e especulação, em dois níveis da cadeia de suprimento, na manufatura e na distribuição, podem alterar o resultado do nível de serviço, como se vê no tabela 1:

Tabela 1 - Matrix 2 × 2 das estratégias de especulação e postergação em logística e manufatura

\begin{tabular}{lccc}
\hline & & \multicolumn{2}{c}{ Logística } \\
\hline Manufatura & Especulação & Especulação & Postergação \\
& Estratégia de & Postergação logística \\
& Postergação & $\begin{array}{c}\text { Postergação de } \\
\text { manufatura }\end{array}$ & Estratégia de \\
& & postergação máxima \\
\hline
\end{tabular}

Fonte: PAGH; COOPER (1998). 
A estratégia de especulação máxima é a mais amplamente utilizada pelas empresas. Nessa estratégia, todas as funções da cadeia, da manufatura ou da logística são executadas antes do pedido do cliente. Na estratégia de postergação da manufatura, os produtos ficam estocados inacabados próximos ao cliente e somente são finalizados quando ocorre o pedido. Na estratégia de postergação logística, os estoques de produtos acabados ficam estocados próximos à manufatura de maneira central, aguardando o pedido para serem enviados ao cliente ou ao ponto de uso. Por último, na estratégia de postergação máxima, o produto somente é fabricado e distribuído quando ocorre o pedido do cliente (PAGH; COOPER, 1998).

As empresas podem mudar dentro dessas opções de estratégia dependendo de variações em seus produtos ou para ganhar escalas de produção e compras em função de aumentos de volume (WEMMERLÖV, 1984). Modelos dinâmicos, que variam ao longo do tempo, também são possíveis e podem ser necessários para melhor adequação à variação momentânea na demanda (LI, 1987).

Portanto, para que o gestor tome cada uma das decisões mostradas acima, necessita-se do conhecimento do nível de serviço desejado e do que ele deseja pagar por ele. Logicamente, vários fatores fazem parte desta decisão, entre elas o conhecimento do produto, da localização dos clientes e fornecedores, do tipo de demanda, etc.

\subsection{Decisões operacionais e o nível de serviço}

Entre as razões para se manter estoques, estão: melhorar o nível de serviço ao cliente, reduzir os custos de aquisição com o aumento de escala, custos mais baixos para emissão de pedidos, custos mais baixos com a falta de estoque, custos mais baixos de qualidade de produção inicial, falta de coordenação nas diversas fases da cadeia, presença de incertezas nas previsões de demanda, especulação e disponibilidade inicial no canal de distribuição. Como contraponto, entre as razões contra o inventário têm-se: custos financeiros na administração dos estoques, custo de capital, custos derivados da perda de flexibilidade para atendimento ao cliente, custos de coordenação da produção, retornos menores sobre os investimentos, custos com redução de capacidade, custos com problemas de qualidade no 
estoque, custos com problemas de produção (GAITHER; FRAZIER, 2002; CORRÊA; CORRÊA, 2008).

Diversos são os modelos propostos para a definição das duas variáveis de um sistema de inventário: o quanto pedir e quando pedir, comumente designados "Q" e "T".

Como o objetivo primário do gerenciamento de estoque é garantir que o produto esteja disponível no tempo e nas quantidades necessárias, o nível de serviço pode ser definido como a probabilidade complementar de haver falta de um determinado produto em relação a sua demanda, dada pela equação 1 (BALLOU, 2006).

Equação 1 - Equação do nível de serviço

Nivel de serviço $=1-\frac{n^{\circ} \text { esperado de unidades faltantes anualmente }}{\text { demanda anual total }}$

Fonte: Ballou (2006).

Considerando a margem de contribuição logística como sendo a diferença entre as receitas relacionadas à logística, advindas do nível de serviço, e os custos logísticos, tem-se o resultado máximo dessa relação no ponto onde a receita marginal para cada ponto adicional do nível de serviço é igual ao custo marginal oriundo desse incremento. Ou seja, cada incremento do nível de serviço gera um incremento de receita igual a um de custo, não gerando nenhum resultado adicional na margem de contribuição (BALLOU, 2006). Graficamente tem-se o comportamento visto na figura 1 :

Figura 1 - Curvas de receita e de custo por nível de serviço

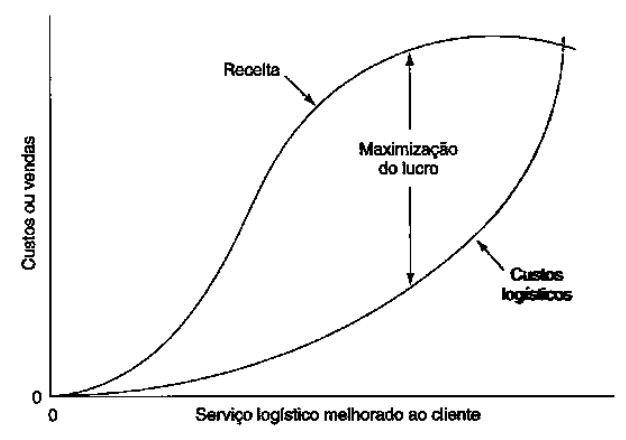

Fonte: Ballou (2006) 
Portanto, o lucro máximo ocorre quando se tem a receita marginal igual ao custo marginal. O significado disso é que, a partir do ponto de lucro máximo, qualquer receita adicional é rapidamente igualada pelo crescimento de igual valor no custo, não gerando nenhum lucro adicional. Matematicamente, deve-se então igualar a primeira derivada da equação $L=R-C$ a zero e então calcular o nível de serviço ótimo:

Equação 2 - Derivação da curva de lucro em função do nível de serviço

$$
L=R-C
$$

Onde:

$\mathrm{L}=$ Margem de contribuição logística

$\mathrm{R}=$ receitas advindas do serviço logístico

$\mathrm{C}=$ custo logístico

$\mathrm{N}=$ nível de serviço

$$
\frac{d L}{d N}=\frac{d R}{d N}-\frac{d C}{d N} \quad \text { Se: } \frac{d L}{d N}=0 \therefore \frac{d R}{d N}=\frac{d C}{d N}
$$

Fonte: Adaptado de Ballou (2006)

Como já mencionado, a logística provê o serviço de tempo e lugar, e a relação entre o nível de serviço e a satisfação provocada nos clientes é muito explorada na literatura de marketing, mas pouco explorada na de operações. Muito embora os níveis de serviço possam ser medidos pelas empresas vendedoras, é a percepção do cliente que mais conta. $\mathrm{Na}$ visão do cliente, nível de serviço pode englobar outras dimensões de produto, qualidade e manutenção, além das operações logísticas (MENTZER; GOMES; KRAPFEL, 1989).

Assim, as competências logísticas devem estar sintonizadas com as necessidades dos clientes e com as condições objetivas internas da organização e do ambiente competitivo na qual a empresa está inserida. Ao aprender com mais precisão as percepções dos clientes, as empresas passam a ter mais elementos para criarem um diferencial competitivo com suas estratégias (CAMPOS, 2008). Elas buscam criar cadeias de suprimentos que produzam níveis de serviço sustentáveis e adequados para cada cliente, não somente por meio da gestão operacional de seus estoques, mas também através de decisões estratégicas e táticas. Essa ideia é corroborada pelo fato de que flexibilidade, dinâmica e foco aos requisitos do cliente podem proporcionar vantagem competitiva às empresas, tanto sobre concorrentes como quanto sobre novos entrantes (OLIVEIRA; OLIVEIRA, 2005). 


\section{METODOLOGIA}

Este trabalho foi conduzido na forma de um estudo de caso usando informações de arquivo de um grande atacadista de autopeças. Trata-se de uma empresa de grande porte com um centro de distribuição central para repor material para algo em torno de 500 pontos de entrega em todo Brasil. Criou-se uma base de dados históricos de custo de inventário, vendas e os respectivos níveis de serviço mensais de 2008 a 2012. De posse desses dados quantitativos, realizou-se uma regressão baseada nos tipos de curva propostos por Ballou (2006), buscando pelas equações resultantes. O estudo de caso foi escolhido por ser aplicável ao teste de teorias desenvolvidas previamente, apoiando assim o objetivo desta pesquisa. $O$ fato da presente pesquisa caracterizar-se como um estudo de apenas uma fonte de dados, sem fazer uso de triangulação, apresenta-se como aparente limitação da metodologia usada (VOSS; TSIKRIKTSIS; FROHLICH, 2002). Entretanto, o uso de apenas uma fonte de pesquisa é as vezes empregado pelos pesquisadores. Considera-se também que existem outros tipos de triangulação, como por exemplo a triangulação entre pesquisadores que poderão usar a metodologia usada neste estudo para outros casos, com o objetivo de aprofundar as conclusões apresentadas nesta pesquisa (YIN, 2001). Pese-se o fato de que as medições de nível de serviço em função dos custos de inventário e receita são, muitas vezes, difíceis de conseguir.

Caracterizando-se o presente estudo como um teste da teoria exposta em Ballou (2006), serão usados os três constructos expostos em sua pesquisa, que serão representados por três variáveis como segue:

Tabela 2 - Relação entre constructos e variáveis

\begin{tabular}{|c|c|c|}
\hline $\begin{array}{c}\text { Constructos segundo } \\
\text { Ballou (2006) }\end{array}$ & Variáveis & Tipo de variável \\
\hline Nível de serviço & Disponibilidade de estoque & Independente \\
\hline Custo logístico & Custo de inventário & Dependente \\
\hline Receita & Receita & Dependente \\
\hline
\end{tabular}

Fonte: Ballou (2006)

A resposta que se pretende obter para verificar se a teoria de Ballou (2006) pode ser aplicada ao caso em estudo é: existe relação de dependência do 
constructo de nível de serviço com os constructos de custo logístico e de receita? Foram feitas regressões de variáveis lineares e não lineares, uma vez que o objetivo da metodologia deve ser o de buscar uma explicação de como o segundo e o terceiro constructos variam separadamente em função do primeiro (GUJARATI; PORTER, 2004).

A literatura apresenta outros métodos para o levantamento prático da curva de inventário pelo nível de serviço e da curva de vendas pelo nível de serviço. Os métodos expostos na literatura requerem o estabelecimento de um alto nível de serviço e, a partir daí, verifica-se o respectivo nível de venda atingido. Então, variase o nível de serviço levantando-se a reação nas vendas. Obviamente, tal modelo apresenta limitações, dado que seria inviável baixar o nível de serviço a níveis muito baixos apenas para ver a reação nas vendas (BALLOU, 2006), além da dificuldade inerente de se realizar medições exatas desse indicador. A regressão feita a partir de leituras históricas, apesar de ser uma aproximação teórica, é uma boa alternativa para a obtenção das curvas e criação das equações de lucro, necessárias para a obtenção do nível de serviço ótimo, sendo uma contribuição metodológica importante para outras discussões sobre o tema dessa pesquisa.

\subsection{Operacionalização das Variáveis}

Uma vez que Ballou (2006) expressa o nível de serviço como sendo a probabilidade de um produto estar disponível, a variável disponibilidade será dada pela porcentagem de linhas de pedido dos clientes que foram atendidas sobre o total de linhas pedidas. O custo logístico será dado pelo custo do material em inventário. A receita será dada pelo resultado das vendas para empresa para seus clientes. As fórmulas para os cálculos encontram-se a seguir:

$$
\begin{aligned}
& \text { Disponibilidade }=\frac{Q \text { tde de linhas de pedido totalmente atendidas }}{\text { total de linhas pedidas }} \\
& \text { Valor de inventário }=\sum_{i=1}^{n} \text { (custo médio de cada item i } \times \text { quantidade de peças de cada item i) }
\end{aligned}
$$




$$
\text { Receita }=\sum_{i=1}^{n} \text { valor de venda bruto do item }{ }^{\text {"ir }}
$$

Onde: pedido = uma ordem de compra do cliente com vários tipos de produto diferentes e uma quantidade de material para cada produto.

De posse de informações de valores históricos de inventário, de vendas e de disponibilidade, buscou-se um relacionamento estatístico entre essas variáveis. Foi possível, através da relação encontrada, obter as curvas de inventário e vendas como função da disponibilidade a partir de técnicas de regressão. Tornou-se possível, então, o cálculo da disponibilidade ótima a partir da derivação da curva de lucro e a localização do ponto de lucro marginal igual à zero. Esse número foi então comparado com o que foi praticado pela empresa.

\section{Passo 1 - Preparação dos dados}

Para que esse objetivo fosse atingido, primeiramente foi conduzida uma análise para averiguar a normalidade das variáveis. O fato de as variáveis possuírem uma distribuição normal de probabilidades é a primeira verificação que deve estar satisfeita para se dar seguimento às análises de regressão e de correlação. A normalidade é um requisito para a representatividade do índice de correlação, para o uso da estatística t de student e da análise de variância ANOVA (TRIOLA, 1998).

\section{Passo 2 - Formação dos agrupamentos}

A segunda etapa do trabalho foi a condução de uma análise de agrupamento dos dados históricos, buscando uma melhor aderência dos dados às análises de normalidade. O agrupamento foi feito utilizando-se o método de Ward, comparando as distâncias euclidianas entre os grupos formados a fim de determinar a quantidade ótima de grupos (MINGOTI, 2005). As análises de normalidade foram refeitas após a formação dos grupos para a averiguação do comportamento dos resultados. Após a comparação dos resultados de normalidade antes e depois da formação dos grupos foram mapeados alguns pontos extremos, ou outliers, que impactaram negativamente o resultado das equações encontradas, o que foi expresso através de 
um baixo coeficiente de regressão linear "r" (TRIOLA, 1998). De uma maneira geral, pode-se dizer que o que mais caracteriza os outliers é que eles apresentam grandes desvios entre as medidas observadas e as calculadas. Como regra geral, elas podem ser retiradas da regressão apenas se elas puderem ser atribuídas a falhas de leitura (GUJARATI; PORTER, 2004). Portanto, os pontos que apresentaram os maiores resíduos padronizados em módulo foram eliminados da regressão uma vez que ganhos de produtividade na gestão do inventário da empresa criaram distorções à série de dados mais recentes.

\section{Passo 3 - Levantamento das curvas de receita e custo de inventário em função da disponibilidade}

$\mathrm{Na}$ terceira etapa do trabalho, foram levantadas as curvas de custo de inventário como função da disponibilidade e da receita como função da disponibilidade. Como as regressões com variáveis não lineares, que obedecem ao padrão descrito na literatura, possuem limitações matemáticas na sua execução, foram feitas regressões com variáveis lineares e não lineares. As regressões foram feitas usando-se os softwares Excel e Statgraphics. As curvas que melhor aderiram aos dados e também ao padrão descrito na literatura foram então derivadas, propiciando o cálculo da disponibilidade ótima. A análise comparativa da aderência de ambas as curvas experimentais aos dados da pesquisa foram feitas no quinto passo da metodologia.

\section{Passo 4 - Avaliação da validade estatística das equações experimentais}

Seguiu-se então para o quarto passo, onde foi feita uma verificação da validade das equações quadráticas e exponenciais levantadas. A primeira validação empregada foi o índice de correlação linear. A segunda foi um teste formal de hipótese do tipo t-student. Esse teste implica na elaboração de duas hipóteses, sendo a primeira $H_{0}: \rho=0$, de que não existe correlação significativa entre as

variáveis e a segunda $H_{1}: \rho \neq 0$, de que existe correlação significativa entre as variáveis (TRIOLA, 1998). A última verificação feita foi uma análise de variância simples ANOVA (ANDEVA). Tal procedimento visa a descrever o impacto de um 
fator "x" em uma variável dependente "y". Comparando-se os valores da estatística F e os valores-P contra os valores críticos foi possível inferir se as variáveis estão relacionadas entre si (TRIOLA, 1998). Todos os valores foram tabulados e comparados com os valores críticos para uma significância de 0,01 .

\section{Passo 5 - Comparação dos índices $\mathbf{R}^{2}$ entre as curvas experimentais lineares $\mathrm{e}$ não lineares}

No quinto passo buscou-se decidir se as curvas não lineares, mais complexas e com limitações matemáticas, representavam melhor os dados reais do que as equações lineares, mais simples. Comparou-se o desempenho de ambas por meio da comparação de seus índices de determinação $R^{2}$. Esse coeficiente leva em consideração a qualidade dos modelos gerados a partir das equações, uma vez que ele exprime o quanto do erro gerado a partir do modelo pode ser explicado por ele (TRIOLA, 1998).

\section{Passo 6 - Comparação dos erros residuais entre as curvas experimentais lineares e não lineares}

O sexto passo visou a reforçar ou não a conclusão do passo anterior. Foram comparados os erros residuais gerados a partir de ambas as curvas. Erros residuais menores denotam menores diferenças médias entre os pontos reais e suas imagens na curva calculada.

\section{Passo 7 - Derivação das curvas e cálculo da disponibilidade ótima}

Finalmente, após as derivações das equações escolhidas nos passos 5 e 6 e do cálculo da disponibilidade ótima, a disponibilidade teórica foi comparada com as médias e as modas dos valores reais buscando por aderência do modelo acadêmico à gestão da empresa.

Entretanto, veem-se duas limitações nesse estudo de caso: o valor mínimo da disponibilidade na série histórica da pesquisa foi de $85 \%$ e não zero o que gerou a necessidade de extrapolação; a segunda foi o fato de a empresa trabalhar com 
demanda empurrada, enfraquecendo o impacto da disponibilidade nas vendas, uma vez que sempre que houve queda da disponibilidade de estoque, os pedidos ficaram aguardando a execução da ordem.

\section{RESULTADOS}

A seguir os resultados são apresentados na mesma sequência da metodologia de cálculo mostrada anteriormente.

Por meio da comparação dos resultados dos cálculos abaixo com os dados da empresa, é verificado que não existem indícios suficientes que apoiem o argumento de que apenas a metodologia usada para obtenção do nível de serviço ótimo basta para a escolha do nível de serviço a ser usado pelas empresas. Dessa maneira, ganham força os contrapontos apresentados na revisão da literatura, mostrando que aspectos mercadológicos também são levados em consideração pelas empresas.

\section{Passo 1 - Preparação dos dados}

Nessa etapa os dados foram colocados no Software Statgraphics, onde foi analisada a normalidade desses dados conforme se vê na figura 2:

Figura 2 - Análise de normalidade e distribuição de frequência das 3 variáveis estudadas

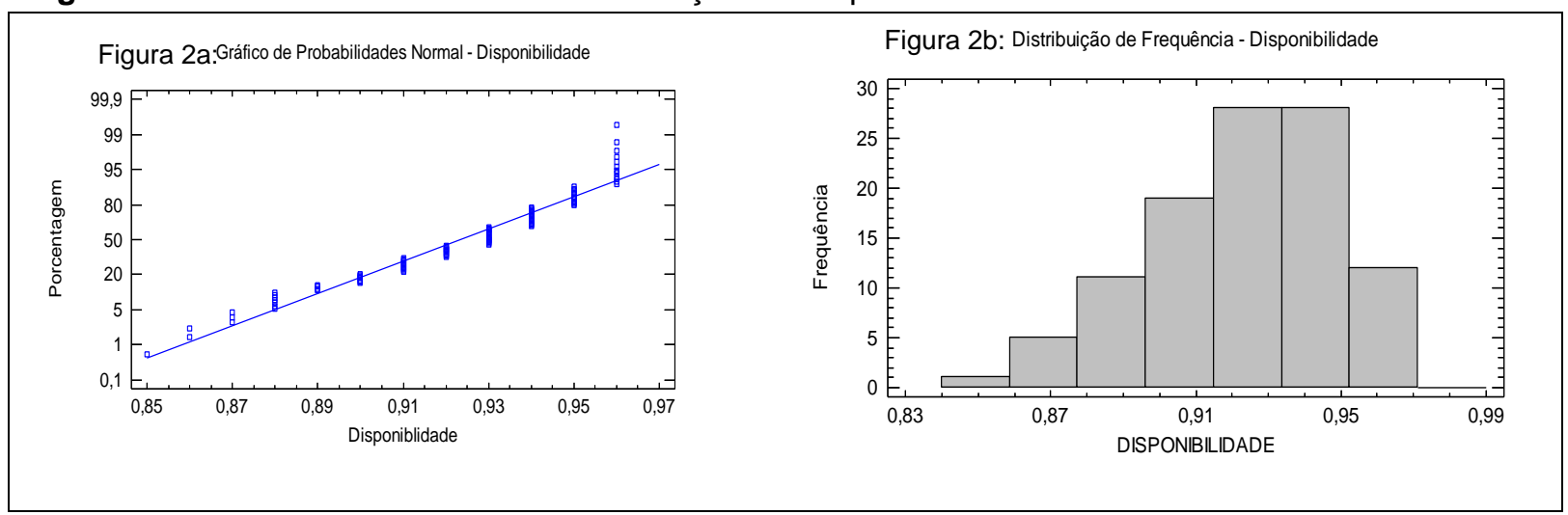

Figura 2c: 


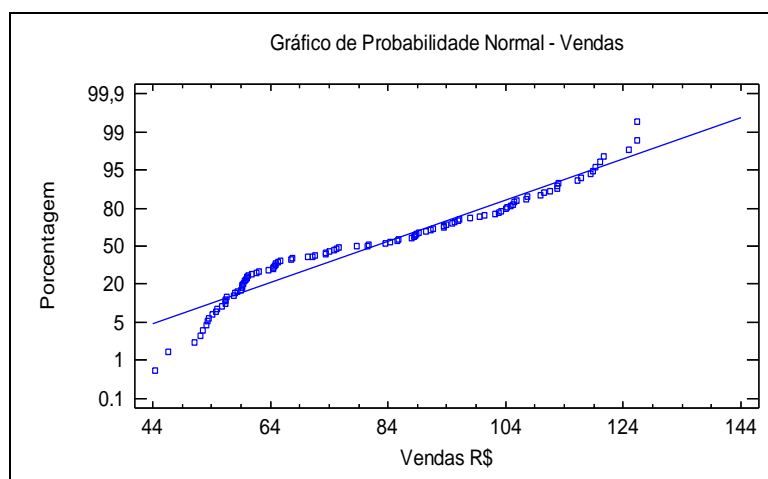

Figura 2d: Distribuição de Frequência - Vendas

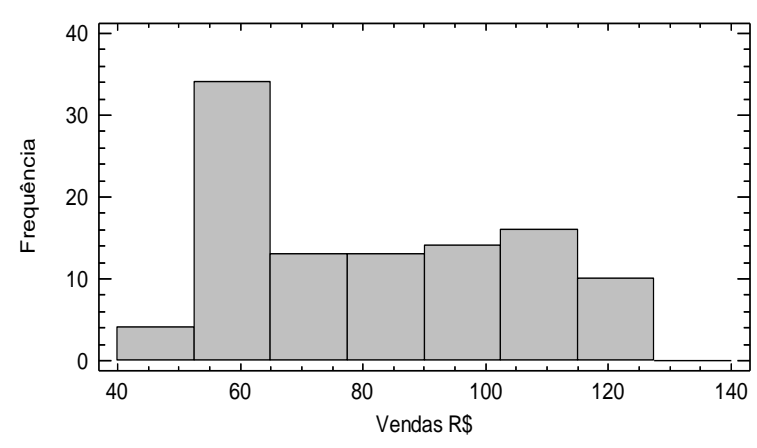

Figura 2e: Gráfico de Probabilidade Normal - Inventário

Figura 2f: Distribuição de Frequência - Inventário
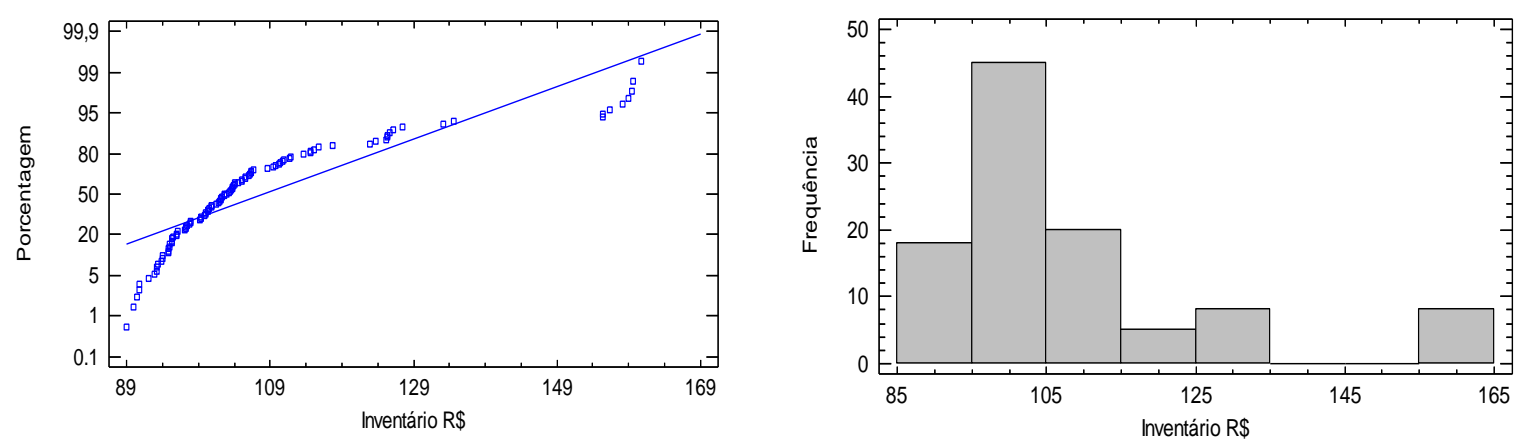

Fonte: Elaboração própria

As linhas retas nas Figuras $2 \mathrm{a}, 2 \mathrm{c}$ e $2 \mathrm{e}$ mostram onde deveriam estar os pontos se as distribuições de frequência fossem normais, isto é, representam as curvas teóricas da distribuição Normal. Na Tabela 3 apresenta-se um resumo estatístico. Vê-se que os pontos não mostram boa aderência às retas, o que é reforçado pelas porcentagens de variação e curtoses dos dados. Portanto as curvas acima não apresentam uma boa normalidade, não permitindo usar esses dados para as regressões pretendidas.

Tabela 3 - Resumo estatístico das curvas normais

\begin{tabular}{ccccc}
\hline Dimensão & Média & Desvio-padrão & \% Variação & Curtosis \\
\hline Disponibilidade & 0,923 & 0,03 & 2,93 & $-0,62$ \\
Inventário & 108,19 & 17,47 & 16,15 & 5,71 \\
Vendas & 81,70 & 22,86 & 27,99 & $-2,55$ \\
\hline
\end{tabular}

Fonte: Elaboração própria

Conclui-se, portanto, que se deve executar algum procedimento adicional para que a necessidade de normalidade imposta pela regressão linear seja 
satisfeita. No passo 2, os dados serão separados em grupos buscando pela satisfação dessa condição inicial para o andamento da metodologia.

\section{Passo 2 - Formação dos agrupamentos}

Com o objetivo de melhorar os resultados de normalidade expostos na tabela 3, foi executada a classificação dos dados originais de disponibilidade, custo de inventário e receita buscando por agrupamentos. Os resultados estão na Figura 3.

Figura 3 - Resultado dos agrupamentos

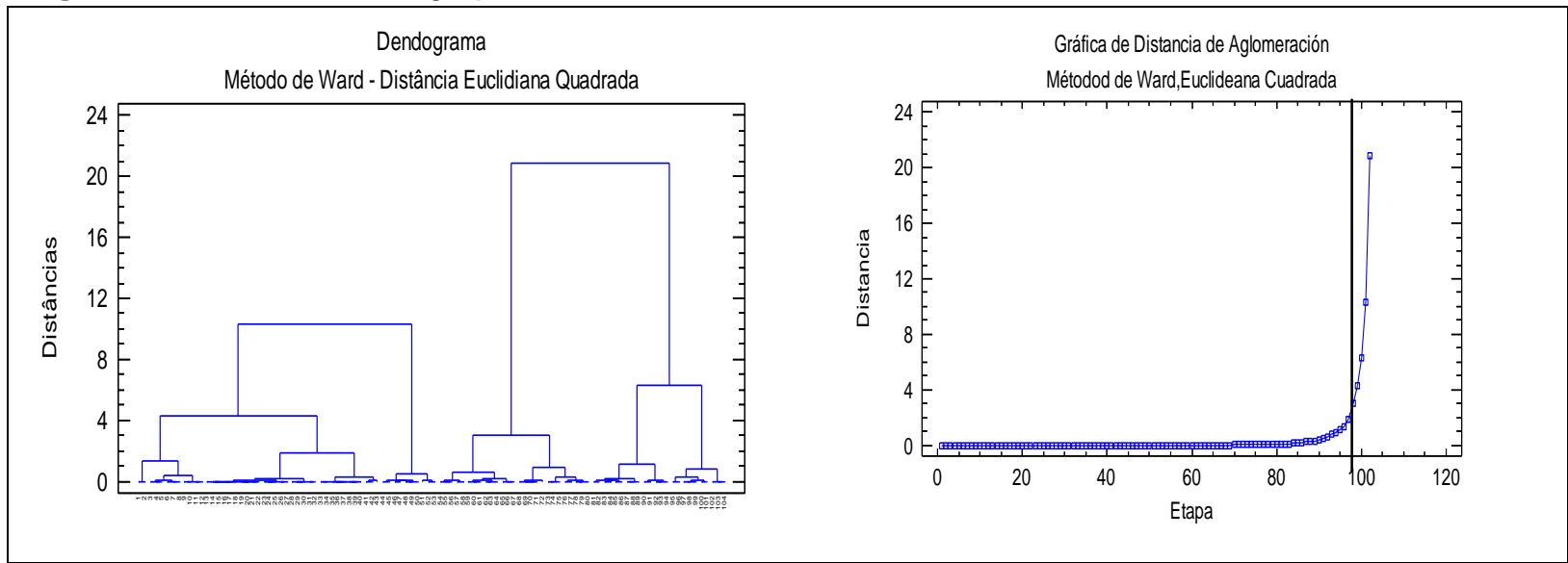

Fonte: Elaboração própria

Diante da forte inflexão no gráfico de distâncias euclidianas, sofrida por volta da etapa 80 do procedimento de formação dos agrupamentos, o software Statgraphics sugeriu dois grupos: o primeiro com 53 membros e o segundo com 51. A mesma análise para avaliação da normalidade do passo 1 foi refeita para cada um dos dois novos grupos formados. Os resultados são apresentados na figura 4. 
Figura 4 - Análise de normalidade e distribuição de frequência das 3 variáveis e nos 2 grupos

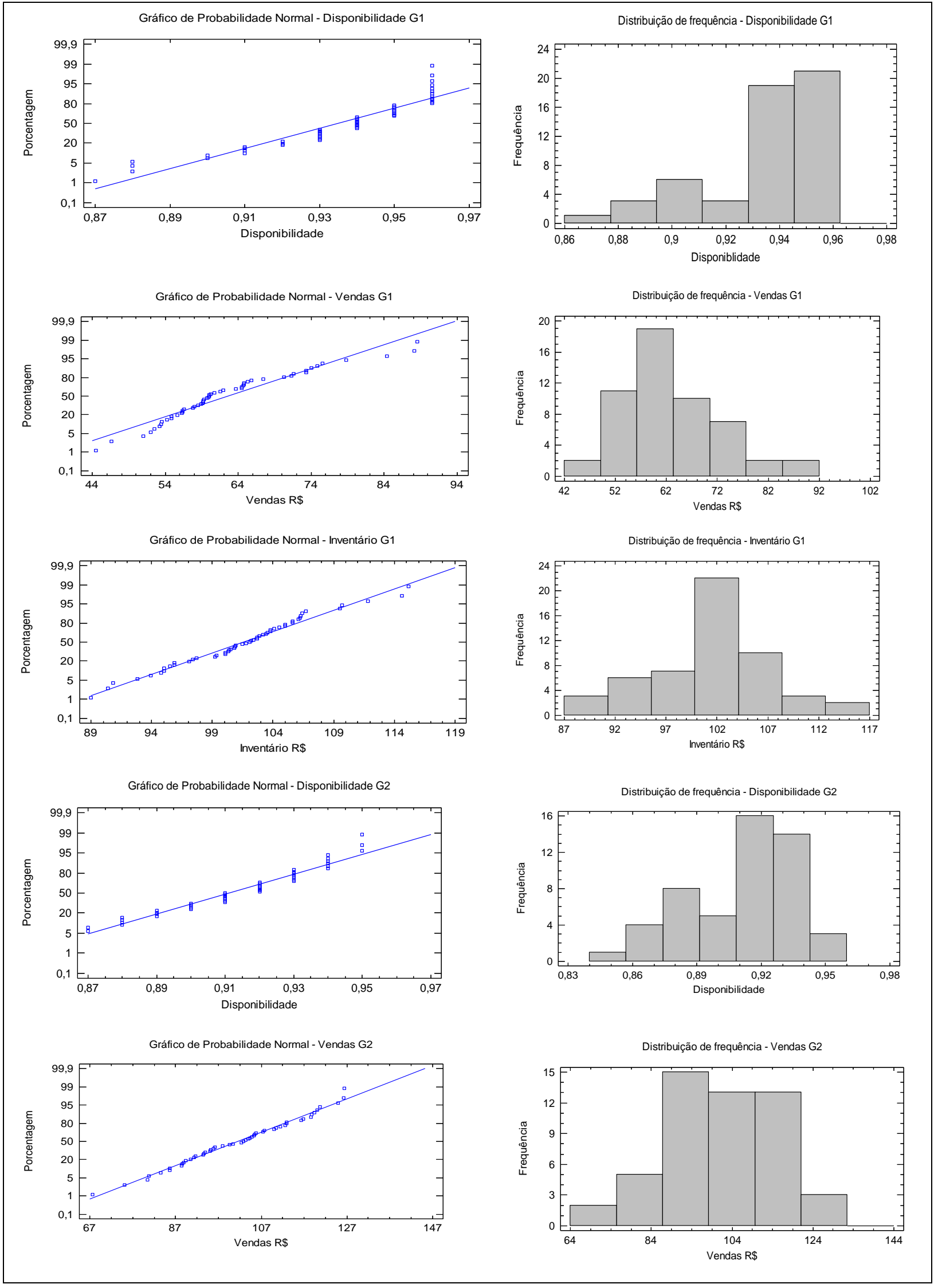

Revista Produção Online, Florianópolis, SC, v.14, n. 4, p.1348-1377, out./dez. 2014. 


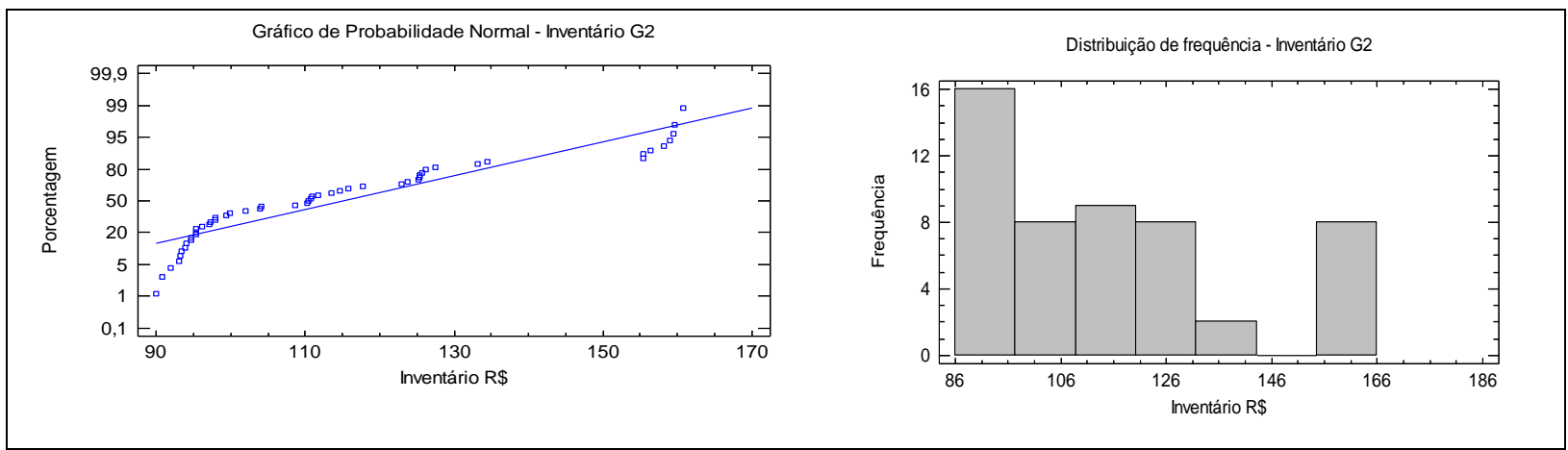

Fonte: Elaboração própria

Os resultados procuram satisfazer a necessidade de normalidade dos dados para prosseguimento dos próximos passos. As análises estatísticas encontram-se resumidas na tabela 4 :

Tabela 4- Resumo estatístico das curvas normais

\begin{tabular}{ccccc}
\hline & Média & Desvio-padrão & \% Variação & Curtosis \\
\hline $\begin{array}{c}\text { Disponibilidade } \\
\text { (Original) }\end{array}$ & $\mathbf{0 , 9 2 3}$ & $\mathbf{0 , 0 3}$ & $\mathbf{2 , 9 3}$ & $\mathbf{- 0 , 6 2}$ \\
Disponib. G1 & 0,932 & 0,03 & 2,78 & $-0,22$ \\
$\begin{array}{c}\text { Disponib. G2 } \\
\text { Inventário }\end{array}$ & 0,912 & 0,02 & 2,59 & 0,48 \\
$\quad$ (Original) & $\mathbf{1 0 8 , 1 9}$ & $\mathbf{1 7 , 4 7}$ & $\mathbf{1 6 , 1 5}$ & $\mathbf{5 , 7 1}$ \\
Inventário G1 & & & & \\
Inventário G2 & 101,48 & 6,21 & 6,13 & $-0,15$ \\
$\quad$ Vendas & 114,05 & 18,99 & 16,66 & 0,48 \\
(Original) & $\mathbf{8 1 , 7 0}$ & $\mathbf{2 2 , 8 6}$ & $\mathbf{2 7 , 9 9}$ & $\mathbf{- 2 , 5 5}$ \\
$\quad$ Vendas G1 & & & & \\
Vendas G2 & 58,10 & 4,99 & 8,59 & 0,52 \\
\hline
\end{tabular}

Fonte: Elaboração própria

Percebe-se, pela análise dos gráficos da figura 4 e da tabela 4 , que as dimensões estatísticas melhoraram sensivelmente quando os dados foram agrupados em 2 grupos menores. Esses dois grupos menores serão chamados doravante de G1 e de G2 para facilitar a identificação dos cálculos que serão separados para cada grupo.

Conclui-se pela apresentação das curvas e dos dados, que houve uma melhor adesão dos dados dos dois grupos a um perfil de distribuição normal de frequência, dando por satisfeita a primeira condição da metodologia. O passo 3 dará início ao cálculo das regressões para levantamento das curvas de receita e custo de inventário em função da disponibilidade. 


\section{Passo 3 - Levantamento das curvas de receita e custo de inventário em função da disponibilidade}

Nessa etapa as curvas de custo de inventário em função da disponibilidade e de receita em função da disponibilidade foram levantadas através do método de regressão. Os resultados podem ser vistos na Figura 5.

Figura 5 - Pontos (x,y) de Disponibilidade x Inventário e Disponibilidade x Receita para cada grupo

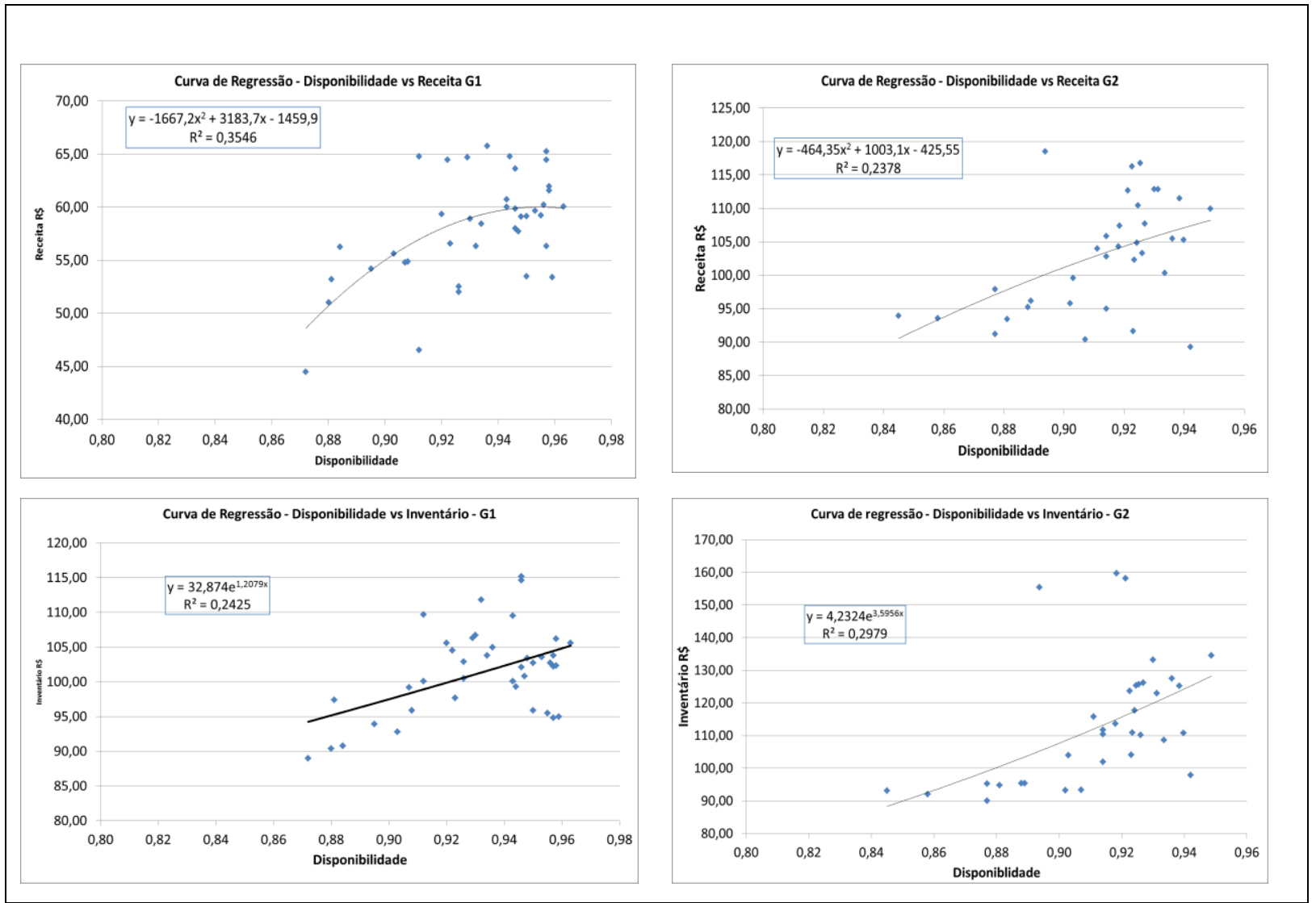

Fonte: Elaboração própria

As equações quadráticas e exponenciais levantadas e expressas pelos gráficos da figura 5, e que podem ser encontradas nas equações 3, 4 (Grupo 1), e equações 5 e 6 (Grupo 2), apresentadas na sequência, representam as curvas de inventário e receita em função da disponibilidade, experimentalmente levantadas.

Equação 3 - Equação experimental de receita como função da disponibilidade para o Grupo 1

$y=-1667,2 x^{2}+3183,7 x-1459,9$

Onde:

$\mathrm{Y}=$ receita

$\mathrm{X}=$ disponibilidade 
Equação 4 - Equação experimental de custo de inventário como função da disponibilidade para o Grupo 1

$y=32,87 e^{1,208 x}$

Onde:

$\mathrm{Y}=$ custo de inventário

$\mathrm{X}=$ disponibilidade

Equação 5 - Equação experimental de receita como função da disponibilidade para o Grupo 2

$y=-464,35 x^{2}+1003,1 x-425,55$

Onde:

$\mathrm{Y}=$ receita

$\mathrm{X}=$ disponibilidade

Equação 6 - Equação experimental de custo de inventário como função da disponibilidade para o Grupo 2

$y=4,23 e^{3,596 x}$

Onde:

$\mathrm{Y}=$ custo de inventário

$\mathrm{X}=$ disponibilidade

O passo 4 buscará pela validade estatística dessas equações permitindo que se faça o cálculo da disponibilidade ótima.

\section{Passo 4 - Avaliação da validade estatística das equações experimentais}

A validade estatística das curvas encontradas no passo 3 foi verificada por meio da comparação do coeficiente de regressão linear "r", do índice "t" de student, do coeficiente de determinação $\mathrm{R}^{2}$, do teste $\mathrm{F}$ e do valor $\mathrm{P}$ para os dados levantados a partir dessas equações com os dados originais.

Equação 7- Cálculo do coeficiente de regressão linear "r"

$$
r=\frac{n \sum x y-\sum x \sum y}{\sqrt{n \sum x^{2}-\left(\sum x\right)^{2} \sqrt{n \sum y^{2}-(\Sigma y)^{2}}}}
$$

Fonte: Triola (1998)

Equação 8 - Cálculo da dimensão "t" de student

$$
t=\frac{r}{\sqrt{\frac{1-r^{2}}{n-2}}}
$$

Fonte: Triola (1998)

Os resultados calculados encontram-se no quadro 1. 
Quadro 1 - Resultados das dimensões estatísticas para os dois grupos

\begin{tabular}{|c|c|c|c|}
\hline $\begin{array}{c}\text { Medida } \\
\text { Grupo } \\
1\end{array}$ & $\begin{array}{c}\text { Receita }= \\
f(\text { Disponibilidade })\end{array}$ & $\begin{array}{c}\text { Inventário = } \\
\mathrm{f}(\text { Disponibilidade })\end{array}$ & $\begin{array}{c}\text { Valor } \\
\text { crítico } \\
\square \tilde{a} !\end{array}$ \\
\hline$r$ & 0,60 & 0,480 & 0,402 \\
\hline$t$ & 4,150 & 3,350 & 2,327 \\
\hline $\mathrm{R}^{2}$ & 0,355 & 0,243 & - \\
\hline$F$ & 3,440 & 3,450 & 7,009 \\
\hline Valor-P & 0,006 & 0,006 & 0,010 \\
\hline
\end{tabular}

\begin{tabular}{|c|c|c|c|}
\hline $\begin{array}{c}\text { Medida } \\
\text { Grupo } \\
2\end{array}$ & $\begin{array}{c}\text { Receita }= \\
f(\text { Disponibilidade) }\end{array}$ & $\begin{array}{c}\text { Inventário }= \\
f(\text { Disponibilidade) }\end{array}$ & $\begin{array}{c}\text { Valor } \\
\text { crítico } \\
\square \tilde{C} .\end{array}$ \\
\hline$r$ & 0,490 & 0,490 & 0,437 \\
\hline $\mathrm{t}$ & 3,150 & 3,210 & 2,327 \\
\hline $\mathrm{R}^{2}$ & 0,238 &, 298 & - \\
\hline $\mathrm{F}$ & 1,630 & 1,900 & 7,054 \\
\hline Valor-P & 0,164 & 0,100 & 0,010 \\
\hline
\end{tabular}

Fonte: Elaboração própria

O quadro 1 mostra que os valores do coeficiente de correlação e da estatística "t" de student são superiores aos valores críticos, assim como os valores da estatística "F" e "valor-p" estão dentro dos valores limites, tudo para uma significância de 0,01. Isso mostra que os dados gerados a partir das equações 3, 4, 5 e 6 possuem representatividade com confiança estatística de $99 \%$. Isso significa que existem elementos suficientes para apoiar o uso das equações como uma representação gráfica dos dados reais levantados nos registros da empresa.

Entretanto, pode-se ver duas limitações dos resultados. A primeira limitação pode ser observada para o grupo 2, pois o Valor-P encontra-se acima do valor crítico. Vale ressaltar que esse valor sofre grande influência do tamanho da amostra (TRIOLA, 1998). A outra limitação é o baixo valor do coeficiente de determinação $R^{2}$. Essa baixa adesão pode dever-se pela necessidade de pesquisa de se explicar as variáveis dependentes, receita e custo de inventário, através de apenas uma variável independente, disponibilidade. O resultado indica que as variáveis dependentes devem variar em função de outras variáveis independentes não expostas e, portanto, seria cabível uma regressão múltipla. Entretanto, esse procedimento não seria condizente com o objetivo dessa pesquisa.

Apesar dos valores-p para o grupo G2 encontrarem-se fora dos parâmetros críticos, os resultados das demais estatísticas dá subsídios suficientes para apoiar a representatividade dos dados através das curvas levantadas no passo 3. Resta ainda a dúvida sobre qual das duas regressões, a de variável linear ou a de variável não linear, representa melhor os dados. O passo 5 fará a comparação dos coeficientes de determinação $\mathrm{R}^{2}$ de ambas as regressões buscando pelo melhor desempenho. 


\section{Passo 5 - Comparação dos índices $\mathbf{R}^{2}$ entre as curvas experimentais lineares e não lineares}

Quando se calculam os coeficientes de determinação $R^{2}$ a partir das regressões de variáveis não lineares e os comparam aos índices calculados a partir das regressões de variáveis lineares têm-se os dados do quadro 2.

Quadro 2 - Comparação entre os coeficientes de determinação do modelo teórico e dos dados da pesquisa

\begin{tabular}{|l|c|c|}
\hline & $\begin{array}{c}\mathrm{R}^{2}-\text { curvas não } \\
\text { lineares }\end{array}$ & $\begin{array}{c}\mathrm{R}^{2} \text {-curvas } \\
\text { lineares }\end{array}$ \\
\hline Eq. 3 Disponib. vs vendas Grupo 1 & 0,3546 & 0,3119 \\
\hline Eq. 4 Disponib. vs inventário Grupo 1 & 0,2425 & 0,2275 \\
\hline Eq. 5 Disponib. vs vendas Grupo 2 & 0,2378 & 0,2362 \\
\hline Eq. 6 Disponib. vs inventário Grupo 2 & 0,2979 & 0,2433 \\
\hline
\end{tabular}

Fonte: Elaboração própria

O quadro 2 mostra coeficientes de determinação levemente melhores para as curvas não lineares, que possuem o perfil previsto na teoria de Ballou (2006) conforme figura 1, do que as curvas lineares que não estão previstas na teoria.

Não se deve dar uma atenção central ao fato de que os valores dos coeficientes de determinação não serem expressivos, uma vez que a simples adição de outras variáveis de explicação aumenta o coeficiente de determinação. Deve-se acrescentar que a comparação entre os coeficientes de determinação de duas regressões é possível quando o tamanho da amostra e a variável dependente são os mesmos entre os modelos (GUJARATI; PORTER, 2004).

Portanto, a pura comparação dos coeficientes de determinação de duas amostras de mesmo tamanho dá subsídios suficientes para indicar que as curvas experimentais propostas pelas equações 3, 4, 5 e 6, aderentes à teoria, representam os dados tão bem quanto as curvas lineares, não aderentes a ela.

\section{Passo 6 - Comparação dos erros padrão entre as curvas experimentais lineares e não lineares}


Os erros padrão das estimativas entre os dois métodos de cálculo foi resumido no quadro 3 :

Quadro 3 - Comparação entre os erros padrão gerados pelas equações lineares e não-lineares

\begin{tabular}{|l|c|c|}
\hline & $\begin{array}{l}\mathrm{s}_{\mathrm{e}}-\text { curvas não } \\
\text { lineares } \\
s_{e}=\sqrt{\frac{\sum(y-\hat{y})^{2}}{n-2}}\end{array}$ & $\begin{array}{c}\mathrm{s}_{\mathrm{e}} \text { - curvas lineares } \\
s_{e}=\sqrt{\frac{\sum(y-\hat{y})^{2}}{n-2}}\end{array}$ \\
\hline Eq. 3 Disponib. vs vendas Grupo 1 & 4,06 & 4,19 \\
\hline Eq. 4 Disponib. vs inventário Grupo 1 & 5,56 & 5,21 \\
\hline Eq. 5 Disponib. vs vendas Grupo 2 & 6,72 & 15,14 \\
\hline Eq. 6 Disponib. vs inventário Grupo 2 & 15,03 & \\
\hline
\end{tabular}

Fonte: Elaboração própria

Vê-se que os erros gerados a partir de ambas as curvas são muito semelhantes, permitindo inferir que as curvas de variáveis não lineares, previstas na literatura, possuem resultados melhores que as lineares, não previstas. Conclui-se que os resultados expressos nos quadros 1, 2 e 3 fornecem indícios suficientes para suportar a validade estatística das equações 3, 4, 5 e 6, levantadas a partir de regressão linear dos dados reais da empresa.

Conclui-se que existem subsídios suficientes para permitir a derivação das equações e o cálculo da disponibilidade ótima, uma vez que as curvas apresentadas apresentam boa aderência aos dados da empresa.

\section{Passo 7 - Derivação das curvas e cálculo do nível de serviço ótimo}

Aplicando a equação 2 para o grupo 1 forma-se a equação 9:

Equação 9 - Equação do lucro para o grupo 1

$$
L=-1667,2 x^{2}+3183,7 x-1459,9-32,87 e^{1,208 x}
$$

Onde:

$$
\begin{aligned}
& \mathrm{L}=\text { Lucro } \\
& \mathrm{X}=\text { disponibilidade }
\end{aligned}
$$

Fonte: Elaboração própria

Para o grupo 2 forma-se a equação 10: 
Equação 10 - Equação do lucro para o grupo 2

$L=-464,35 x^{2}+1003,1 x-425,55-4,23 e^{3,596 x}$

Onde:

$\mathrm{L}=\mathrm{Lucro}$

$\mathrm{X}=$ disponibilidade

Fonte: Elaboração própria

Derivando-se os dois conjuntos de equações em função da disponibilidade $(\mathrm{x})$, e igualando as equações a zero tem-se:

Para o grupo 1:

Equação 11 - Derivada da equação 9 em função da disponibilidade (x)

$$
\frac{d L}{d x}=-3334,4 x+3183,7-39,71 e^{1,208 x}=\mathbf{0}
$$

Fonte: Elaboração própria

Para o grupo 2:

Equação 12 - Derivada da equação 10 em função da disponibilidade $(\mathrm{x})$

$$
\frac{d L}{d x}=-928,7 x+1003,1-15,22 e^{3,596 x}=\mathbf{0}
$$

Fonte: Elaboração própria

As disponibilidades ótimas calculadas a partir da solução das equações $11 \mathrm{e}$ 12, são:

- grupo $1=>91,9 \%$

- grupo $2=>79,5 \%$

A moda e a média das disponibilidades reais praticados em cada grupo de dados têm o comportamento como o visto na tabela 5:

Tabela 5 - Exibição da moda e da mediada calculadas a partir dos dados reais da pesquisa

\begin{tabular}{lccc}
\hline & Resultados das equações 11 e 12 & Moda & Medias \\
\hline Grupo 1 & $91,9 \%$ & $95,7 \%$ & $93,2 \%$ \\
Grupo 2 & $79,5 \%$ & $91,4 \%$ & $91,3 \%$ \\
\hline
\end{tabular}

Fonte: Elaboração própria

\section{DISCUSSÃO DOS RESULTADOS}

Levantando-se os erros entre as amostras para os dois grupos de dados e os valores calculados a partir das equações, que seriam os valores do nível de serviço ótimo levantado a partir do arcabouço teórico usado nessa pesquisa, tem-se:

- Para o G1: 1,3\% de erro em relação à média e $4 \%$ em relação à moda 
- Para o G2: $11,8 \%$ de erro em relação à média e $13 \%$ em relação à moda

Em função dos baixos erros relativos, pode-se dizer que o primeiro grupo de dados apresenta uma boa aderência aos modelos expostos na teoria, validando portanto a teoria de Ballou (2006).

O mesmo já não acontece para o segundo grupamento de dados, que apresenta problemas de aderência às equações propostas pela teoria, além dos resultados apresentarem erros relativos maiores. Caso a empresa usasse o modelo proposto pela literatura, seria esperado que os valores, para ambos os grupamentos, possuíssem erros pequenos entre os modelos propostos pela literatura e os calculados a partir dos dados reais.

Nota-se ainda que os valores calculados pelos modelos da teoria são consistentemente menores que o valores médios praticados pela empresa, fato esse que pode denotar que a empresa procura sistematicamente por níveis de disponibilidade maiores dos que seriam economicamente viáveis.

Portanto, a pura comparação entre as modas e as médias dos níveis de serviço reais praticados pela empresa estudada, desde 2004, com os valores calculados pela metodologia proposta, mostra que não existem argumentos que apoiem a conclusão de que apenas o modelo de Ballou (2006) de nível de serviço ótimo seja considerado para decisão de qual nível de serviço deve ser usado na gestão da empresa, dados os resultados díspares para cada grupamento na tabela 5. Ao contrário, existem evidências de que tais decisões são baseadas em experiência dos gestores, questões ambientais e competitivas. Ademais, existem conceitos apresentados na revisão da literatura que apoiam o fato de que, cada vez mais, o serviço logístico é um diferencial competitivo das empresas e, dessa maneira, representa uma vantagem única e de difícil equiparação no jogo das empresas (MENTZER; WILLIAMS, 2001; JUNIOR, MIYAKE; 2011; EMERSON, GRIM; 1996; SLACK; CHAMBERS; JOHNSTON, 2007). 


\section{CONSIDERAÇÕES FINAIS}

O objetivo dessa pesquisa foi avaliar o nível de serviço logístico ótimo praticado por uma empresa atacadista de autopeças. Por meio da aplicação da teoria segundo Ballou (2006), criaram-se dois grupos de equações de custo de inventário e receita em função da disponibilidade que foram comparados com os números praticados atualmente pela empresa para atendimento do seu nível de serviço logístico.

Essa pesquisa não pretendeu avaliar exatamente quais fatores influenciam as decisões sobre o nível de serviço que será praticado, e sim mostrar que essas decisões nem sempre são apoiadas nos métodos quantitativos explorados na literatura, mas são frutos de métodos heurísticos apoiados em experiências pessoais e no ambiente competitivo. Não se pretendeu também um julgamento definitivo de valor se o nível de serviço praticado pela empresa é adequado ou não, ou qual deveria ser o valor do nível de serviço praticado para a empresa estudada.

Apesar dos resultados apresentados não poderem ser generalizados, a relevância dessa pesquisa é dada pelo seu caráter inovador abrindo a discussão sobre como definir o nível de serviço ideal para estoque. Uma continuidade natural desse trabalho é aprofundar mais as investigações procedendo a triangulação dos dados usando-se outras fontes de pesquisa, além da investigação de outros fatores qualitativos e ambientais que possam influenciar os jogos entre os competidores. Esses fatores devem pertencer a mais de uma dimensão, que vai além da mera disponibilidade de estoque, onde entrariam, por exemplo, relacionamento com o cliente, percepção de qualidade pelo comprador, relação contratual entre comprador e vendedor, competitividade do fornecedor entre outros. Seguindo esse raciocínio, empresas que possuem relacionamento direto com os consumidores finais e em ambientes altamente competitivos parecem praticar níveis de serviço maiores, uma vez que os impactos para a marca e a perda de receitas são mais importantes nesse tipo de negócio. Relacionamentos contratuais, por sua vez, podem estabelecer níveis de serviço mínimos muito maiores que os considerados ótimos pelo fornecedor, assim como a falta de concorrência pode manter o nível de serviço dos fornecedores em níveis menores. 


\section{REFERÊNCIAS}

BALLOU, R. H. Gerenciamento da cadeia de suprimentos/logística empresarial. Porto Alegre: Bookman, 2006.

CAMPOS, D. F. Um estudo das percepções de gestores e clientes do serviço oferecido aos pequenos varejistas do setor alimentar. RAM Revista de

Administração Makenzie, v.9, n. 3, p. 85-114, 2008.

http://dx.doi.org/10.1590/S1678-69712008000300005

CORRÊA, H.; CORRÊA, C. Administração de produção e de operações. São

Paulo: Editora Atlas, 2008.

DE LEEUW, S.; VAN GOOR, AD R.; VAN AMSTEL, R. P.The selection of distribution control techmiques. The International Journal of Logistics Management, v. 10, n. 1, p. 97-110, 1999. http://dx.doi.org/10.1108/09574099910805888

EMERSON, C. J.; GRIMM, C. M. Logistics and marketing components of customer service: An empirical test of the Mentzer, Gomes and Krapfel model. International Journal of Physical Distribution \& Logistics Management, v. 26 n. 8, pp. 29-42, 1996. http://dx.doi.org/10.1108/09600039610128258

FERREIRA, H. S. R.; ALCÂNTRA, R. L. C. Mecanismos de coordenação no canal de distribuição automotivo: algumas contribuições. Revista Produção Online.

Florianópolis, SC, v.11, n. 3, p. 619-647, jul./set. 2011.

http://dx.doi.org/10.14488/1676-1901.v11i3.461

FREITAS, L. M.; DINIZ, A. C. M.; LEITE, M. S. A.; VILLAR, A. M. Os reflexos do efeito chicote nos custos logísticos de estoque: o caso de uma empresa componente da cadeia de suprimento de bebidas. Revista Produção Online. Florianópolis, SC, v. 10, n. 2, jun. 2010. http://dx.doi.org/10.14488/1676-1901.v10i2.401

GAITHER, N.; FRAZIER, G. Administração da produção e operações. São Paulo: Editora Cengage Learning Edições LTDA, 2002.

GAVIOLLI,L. S.; BARBIERI, J. C. Política de vendas e estoques, baseada em sistemas de classificação de produtos: desenvolvimento teórico e sua aplicação em empresa do setor eletro-eletrônico. Gestão \& Regionalidade, v. 23, n. 66, p. 18-28, jan-abr/2007.

GUJARATI, D. N.; PORTER, D. C.: Basic econometrics. New York: Mc Graw Hill, 2004.

HITT, M. A.; IRELAND, R. D.; HOSKISSON, R. E. Strategic management competitiveness and globalization. Ohio: South-Western, 2003.

JUNIOR, N. T.; MIYAKI, D. I. Melhoria de desempenho em serviços: alternativas para lidar com trade off entre eficiência e eficácia. Revista Produção Online, v.11, n.1, p. 162-193, mar., 2011. http://dx.doi.org/10.14488/1676-1901.v1111.539 
KONIJNENDIJK, P. A. Setting customer service levels: an overall cost-approach. International Journal of Production Economics, v. 23, p. 39-146, 1991. http://dx.doi.org/10.1016/0925-5273(91)90057-Z

KOTLER, P.; ARMSTRONG,G. Princípios de marketing. Rio de Janeiro: Editora LTC - Livros Técnicos e Científicos Editora S.A., 1998. Prentice-Hall, Inc.: 1995.

LI, L. Make to order vs. Make to stock: the role of inventory in delivery - time competition. Massachussets Institute of Technology, 1987.

MANKIW, N. G. Introdução à macroeconomia. Rio de Janeiro: Editora Campus, 2001.

MARCHESINI, M. M. P.; ALCÂNTRA, R. L. C. Conceituando o serviço logístico e seus elementos. Revista de Ciência \& Tecnologia, v. 17, n. 33, p. 65-86, jan./jun. 2012.

MENTZER, T. J.; GOMES, R.; KRAPFEL, JR.; R. E. Physical distribution service: a fundamental marketingconcept? Journal of the Academy of Marketing

Science,v.17, n. 1, pages 53-62, 1989. http://dx.doi.org/10.1007/BF02726354

MENTZER, J. T.; WILLIAMS, L. R.The Role of logistics leverage in marketing strategy. Journal of Marketing Channels, v. 8(3/4) 2001.The Haworth Press, Inc.

MINGOTI, S. A. Introdução à estatísticamultivariada. Belo Horizonte: Editora UFMG, 2005.

OLIVEIRA E SILVA, M. F.; BERTRAND, H. Supply chain, satisfação dos clientes e o custo dos inventários: um modelo para otimização. RAC Eletrônica, Curitiba, v. 2, n. 2, art. 4, p. 218-233, Maio/Agosto.

OLIVEIRA, J. L. R. de; OLIVEIRA, S. L. de. Logística de distribuição e controle de estoques em uma distribuidora de medicamentos. Revista Produção Online, v.5, n.3, set. 2005. http://dx.doi.org/10.14488/1676-1901.v5i3.361

PAGH, J. D.; COOPER, M. C. Supply chain postponement and speculation strategies: how to choose the right strategy. Journal of business logistics, v. 19, n. 2, p. 13-33, 1998.

SLACK, N.; CHAMBERS, S; JOHNSTON, R. Administração da produção.São Paulo: Editora Atlas, 2007.

TRIOLA, M. F. Introdução à estatística. Rio de Janeiro: LTC - Livros Técnicos e Científicos Editora S.A., 1998. Addison Wesley Longman, Inc.

VOSS, C.; TSIKRIKTSIS, N.; FROHLICH, M. Case research in operations Management. International Journal of Operations \& Production Management, v. 22 n. 2, p. 195-219, 2002. http://dx.doi.org/10.1108/01443570210414329 
WANKE, P. F.Dinâmica da estratégia logística em empresas brasileiras. RAE, v.45, n. 4, p. 22-35, Out/Dez 2005. http://dx.doi.org/10.1590/S0104-530X2006000100002

WANKE, P. F.; ARKADER, R.; LOPES, P. H.; RODRIGUES, A. M. Um Estudo sobre os impactos no varejo das principais decisões estratégicas de produção e distribuição da indústria. Gestão \& Produção, v.13, n.1, p.1-13, jan.-abr. 2006.

WEMMERLÖV, U. Assemble-to-order manufacturing: implications for materials management. Journal Of Operations Management, v. 4. No. 4, 1984. http://dx.doi.org/10.1016/0272-6963(84)90021-4

WHYBARK, D. C.; YANG, S. Positioning Inventories in distribution systems. International Journal of Production Economics, v.45, p.271-278, 1996.

WRIGHT, P.; KROLL, M. J.; PARNELL, J. Administração estratégica. São Paulo: Editora Atlas, 2000.

YIN, R. K. Estudo de caso: planejamento e métodos. Porto Alegre: Bookman, 2010 Ed. 4. http://dx.doi.org/10.1016/0925-5273(95)00150-6.

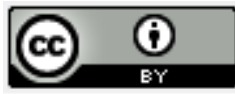

Artigo recebido em 18/08/2013 e aceito para publicação em 30/10/2014 DOI: http://dx.doi.org/ 10.14488/1676-1901.v14i4.1657 